\title{
La política como resistencia, la vulnerabilidad y algunos cabos sueltos ${ }^{1}$ Policy as Resistance, Vulnerability and Some Loose Ends
}

\author{
Ángeles J. Perona*
}

Universidad Complutense de Madrid

RESUMEN. La noción butleriana de política como resistencia destaca por su originalidad, pues se dobla de performatividad y, al mismo tiempo, está abierta a las alianzas. En este texto se argumenta que su singularidad proviene del marco teórico materialista elaborado por Butler, pues ofrece una caracterización de los seres humanos que los vincula socialmente por su mutua dependencia y vulnerabilidad. Finalmente, comentaré tres aspectos confusos o problemáticos de la propuesta butleriana: el primero relacionado con la reconciliación, el segundo con la emancipación y el tercero con la universalidad.

Palabras clave: resistencia; mutua dependencia; vulnerabilidad; reconciliación; emancipación; universalidad.
ABSTRACT. Butlerian notion of politics as resistance stands out for its originality, as it includes performativity and, at the same time, an openness to alliances. In this text I will argued that its singularity comes from the materialistic theoretical framework elaborated by Butler, since she portrays human beings as being socially tied by their mutual dependence and vulnerability. Finally, I will comment on three confused or problematic aspects of Butler's proposal: the first related to reconciliation, the second with emancipation and the third with universality

Key words: Resistance; mutual dependence; vulnerability; reconciliation; emancipation; universality.

${ }^{1}$ Texto elaborado en el marco de los siguientes proyectos: Ministerio de Economía, Industria y Competitividad FFI2016-77755-R y PR26/16-20264 (Banco Santander-Universidad Complutense de Madrid).

*anperona@filos.ucm.es ORCID iD: http://orcid.org/0000-0002-3450-5408. 


\section{EL FONDO MATERIALISTA DE LA POLÍTICA COMO RESISTENCIA}

En una entrevista realizada en 2008, Judith Butler afirma lo siguiente de su trayectoria intelectual: "Empecé trabajando sobre Hegel, después sobre el género, el cuerpo, el lenguaje y la psique, y ahora me he centrado en la responsabilidad ética y política" (Butler 2011,68). En estas pocas líneas expresa lo esencial de los cambios acontecidos en su recorrido intelectual; cambios que hacen de su pensamiento una indagación y no la instauración de una doctrina acabada e inamovible.

Pero, a pesar de los cambios, hay algunos aspectos centrales de su reflexión que se mantienen a lo largo de su trayectoria intelectual. Así, en sus últimos textos conserva el interés que dominó los primeros; me refiero a la atención central sobre una ontología social que, si se me permite la expresión, parece guiada por el intento de responder a la pregunta kantiana sobre qué es el hombre, pero actualizada y reconvertida en la pregunta más inclusiva sobre qué es un ser humano en tanto que cuerpo sexuado, generizado. Su muy conocida respuesta disolvió cualquier resquicio imaginable de esencialismo al sostener que todos los rasgos de identidad humana son fruto de una construcción social y discursiva, lo cual incluye al sexo y no sólo al género. De este modo, su perspectiva de análisis postestructuralista coincidió con los estudios postmodernos de la subjetividad en la idea de que no hay rasgos de identidad previos a los contextos y los $\operatorname{marcos}^{2}$ en los que llegamos a ser lo que somos. Por el contrario, la identidad se efectúa realizando las normas de género vigentes en el marco en el que vivimos.

Desde ahí, y pese a las implicaciones deterministas que pueden derivarse de este enfoque, Butler ofreció un concepto de política como performatividad. En sus obras presenta la performatividad como la iteración de las normas cuyo resultado es la asignación de género. Dicho de otro modo, la performatividad es el proceso por el que cada cual es representado sin todavía ser capaz de entender cómo las normas de género le conforman. Pero la performatividad no se reduce a eso, puesto que también conlleva posibilidades para realizar desviaciones de las normas. Y es que en la propia iteración se abre la posibilidad de la libertad, entendida ésta como un desvío voluntario de las normas que permite conformar identidades de género diferentes.

Fueron muchas las críticas que recibieron las primeras versiones del pensamiento de Butler. Entre otras cosas, se le señaló un exceso de constructivismo

${ }^{2}$ Butler distingue entre marco y contexto, de manera que un marco es lo que delimita un contexto. Un marco es un modo de inteligibilidad, es decir, un conjunto de esquemas históricos que establecen, condicionan y producen lo reconocible en distintos contextos histórico-culturales. Cf. Butler 2010, 20-29. 
que parecía comportar la idea (antirrealista) de que no hubiera límites materiales para las posibilidades de llevar a cabo la construcción identitaria diferenciada de los cuerpos humanos. Por otro lado, se le acusó de disolver el sujeto político del feminismo y, por tanto, de debilitar la lucha feminista en favor de un voluntarismo político de género de corte individualista ${ }^{3}$.

Pero, como he dicho antes, la actitud filosófica de Butler no es la de instaurar y defender una doctrina, sino la de indagar, por eso siempre recoge las críticas y reajusta o perfila su pensamiento en atención a ellas. Así se entiende su esfuerzo reiterado por subrayar que su perspectiva es materialista y, en relación con ello, que "la construcción no sustituye la referencialidad" (Butler 2011, 71). Esta expresión tan técnica tiene su origen remoto en la distinción clásica de raíz fregeana entre la "referencia" y el "sentido" de una expresión lingüística. Teniendo esto en cuenta, lo que manifiesta Butler es que los cuerpos (humanos) se refieren a (mencionan) una realidad material, aunque solo adquieren sentido para los propios seres humanos a través del uso social de nuestros lenguajes para representarlos. En esta medida, lo que un cuerpo es o, lo que es lo mismo, su identidad nace de la interacción social y discursiva. Evidentemente, la distinción entre la referencia material de un cuerpo y su sentido es analítica, puesto que nunca podemos atrapar cognitivamente un cuerpo al margen de la construcción socio-discursiva del mismo. De ahí que descripción y construcción acontezcan al mismo tiempo. Esto permite entender la muy discutida afirmación butleriana de que incluso el sexo biológico sea algo construido.

Con todo, como señalaré más adelante, es muy relevante que Butler enmarque el constructivismo antiesencialista en un materialismo, y todavía es más relevante que a partir de un determinado momento su reflexión acentúe la conexión conceptual de su materialismo con las nociones de dependencia y vulnerabilidad. Esto la lleva a perfilar mejor y de forma más original su manera de entender la acción política.

Antes de seguir por esa vía recordaré brevemente que a la acusación de voluntarismo político y de disolución del sujeto del feminismo Butler respondió ofreciendo una nueva concepción de ese sujeto colectivo (y cualquier otro). A este respecto lo que Butler hace es insertar el constructivismo antiesencialista en un modelo político de democracia radical ${ }^{4}$. Así, entiende que el sujeto político del feminismo (como otros sujetos colectivos) no es un sujeto "natural", es decir, aunado por alguna característica distintiva e independiente de los mar-

${ }^{3}$ Cf. para la segunda cuestión Benhabib 1995. De la primera cuestión me ocupé en Perona 2003.

${ }^{4}$ Cf., por ejemplo, Butler 2011, 42, donde la filósofa se presenta a sí misma como integrante del movimiento queer que valora la libertad como parte de la lucha por la igualdad social, "como el anarquismo y los proyectos de democracia radical". 
cos y contextos de discurso. Por el contrario, los sujetos colectivos también adquieren su identidad política mediante una construcción socio-discursiva diferenciada, es decir, excluyendo características que de por sí darían lugar a la formación de otras posibles identidades de sujeto.

De cualquier modo, la filosofía política de Butler se ha perfilado según ha ido extrayendo las implicaciones de haber enmarcado el constructivismo antiesencialista en el materialismo. La propia pensadora adjetiva ese materialismo como nuevo, y lo es si se compara con el materialismo histórico tradicional de la izquierda política occidental. Una diferencia fundamental entre ambos es que para el nuevo materialismo resulta de suma importancia reparar en que hay nuevas formas de opresión y desposesión, que no se captan desde un único conjunto de condiciones normativas de la identidad, vale decir, desde las normas de clase económico-social. En este sentido, no habría razones suficientes para sostener que los otros conjuntos de condiciones normativas de identidad (como el de género o el de raza, por mencionar los más citados) sean subsidiarios o reductibles al de clase. A propósito de esto Butler ofrece una reconsideración de la política democrática de izquierdas que está alejada de lo que denomina como "marxismos neoconservadores" (Butler 2000, 112). En concreto, se suma a la idea de que no es posible ni deseable unificar los movimientos sociales a base de reducir sus diversas identidades y demandas a una sola, pues eso invisibilizaría y excluiría sin remedio a muchas de esas identidades y sus correspondientes conflictos. La solución que Butler contempla es mantener cada uno de los conflictos de manera que sean políticamente visibles y productivos.

A propósito de este tema hay, al menos, dos cuestiones destacables. La primera sería si la nuda performatividad es la concepción política que Butler ofrece para hacer frente a la opresión y desposesión que acompaña a ciertos grupos identitarios, como los de género. La segunda sería cómo entiende Butler la relación entre su concepción política y la redistribución, en tanto que esta última es la idea característica de la política tradicional de la izquierda occidental.

Respecto de la primera cuestión es preciso señalar que, a lo largo del desarrollo de su teoría la concepción política de Butler adquiere un rasgo característico distintivo, pues acentuará que además de una actividad performativa es, al mismo tiempo, una actividad de resistencia.

Ciertamente la noción de política como resistencia no es nueva, pero las versiones contemporáneas de la misma la han remozado de forma notable. Tal es el caso de la brillante propuesta llevada a cabo por Judith Butler. Su reconceptualización tiene rasgos muy novedosos que se derivan del marco teórico materialista de su pensamiento. Entre esos rasgos está el que su concepto de resistencia se concreta, en primer lugar, como oposición a las nuevos reduccio- 
nismos de izquierda, a las nuevas domesticaciones y subordinaciones. Es preciso resaltar que esta acepción de la política como resistencia no tiene como objetivo político inmediato el propio de la performatividad, es decir, la consecución de la instauración de identidades y vidas alternativas a las regidas por las normas de género hegemónicas, sino que su fruto inmediato sería garantizar una actitud democrática para la izquierda. Es decir, que el principal resultado político de la resistencia así entendida sería el de fortalecer la propia democracia.

En cuanto a la segunda cuestión, Butler deja claro que la resistencia política como defensa de la no reducción identitaria de los sujetos políticos y sus demandas no excluiría la posibilidad de que los diversos colectivos en liza se coaligaran políticamente cuando fuera necesario y posible. Es decir, que las acciones políticas encaminadas a acabar con la opresión identitaria de género podrían aliarse contingentemente con las que se enfrentan a la opresión económica y a otras opresiones y desposesiones. Por tanto, las políticas performativas de resistencia podrían aliarse con las redistributivas ${ }^{5}$. Retomaré este tema un poco más adelante para precisar los términos en los que Butler concibe las alianzas políticas.

Al hilo de esta cuestión de las alianzas políticas hay una precisión interesante que hace Butler: esta nueva política de izquierda de alianzas contingentes no se apoya en ningún presupuesto universal estático. Sin embargo, no rechaza los universales, aunque los entiende como un destello que cobra existencia durante un período limitado en los lugares donde se sitúa el poder (Butler 2000,114). Como defenderé más adelante, esta cuestión de los universales es absolutamente importante, puesto que es la condición de posibilidad de las políticas de solidaridad (redistributivas) y de las políticas emancipatorias, así como de cualquier defensa de la extensión de los derechos por razones de identidad.

Antes de ir a todo ello, es necesario retornar a la noción butleriana de política como resistencia para precisarla algo más, pues no la reduce a la menciona oposición a los nuevos reduccionismos de izquierda.

En efecto, Butler entiende la resistencia también y fundamentalmente como oposición a las normas de identidad que operan de manera hegemónica en las sociedades occidentales. Las normas que centran el interés primordial de Butler son las de género y en torno a ellas elabora su noción de política. Sin embargo, esa noción se ha hecho más general desde el momento en que Butler incluyó en su reflexión el grave problema europeo de los inmigrantes y las guerras y atentados

\footnotetext{
${ }^{5}$ Sobre las posibilidades y dificultades de articular las políticas de resistencia performativa y las redistributivas es muy instructivo el debate que mantuvieron J. Butler y Nancy Fraser. Cf. Butler 2000 y Fraser 2000.
} 
de las últimas décadas. Desde esa perspectiva ampliada Butler explica cómo a través de la iteración de las normas el poder hegemónico instituye un marco delimitador de las vidas pensables. El reverso de ello es que simultáneamente condena a la marginalidad de lo impensable las vidas de quienes quedan excluidos de sus límites (Butler 2011,24). Junto a esto, es preciso destacar que esta oposición política a la realización de las normas hegemónicas (de género) no implica ni nihilismo, ni regodeo estoico en la marginalidad. Por el contrario, el objetivo es modificar las normas, mejor dicho, sus $\operatorname{marcos}^{6}$ y sus efectos de marginalización. Es pues, una actividad tan opositora como forjadora de novedad.

Así pues, la resistencia está conceptualmente enlazada con la performatividad y la identidad, lo cual en el pensamiento de Butler descansa inevitablemente en su particular noción materialista de cuerpo. Se trata de un concepto complejo con varios niveles de significado. Para empezar y como se ha dicho al principio, cuerpo alude a materia, esto es, a un referente que solo adquiere pleno significado en la interacción social y discursiva. Esto conlleva que un cuerpo solo adquiere sentido cuando es tomado en consideración por otro cuerpo. Esta es una caracterización muy general, pero Butler la concreta cuando precisa que todo cuerpo se define por las relaciones e infraestructuras que hacen posible su vida y sus acciones. De ahí concluye que todo cuerpo es dependiente de otros cuerpos y de determinadas redes de apoyo (Butler 2015). La mutua dependencia aparece así como originaria y también como constitutiva de cada cuerpo humano, dado que, como señalábamos al principio, todo cuerpo recibe al margen de su voluntad una asignación de género, la cual consiste en recibir la aplicación de unas normas que nos preceden y que existen en estructuras institucionales del mundo social que nos rodea. Esas estructuras institucionales son fundamentales, pues sirven de apoyo a las vidas pensables en su marco.

A partir de aquí explica Butler que todo cuerpo posee la condición de ser afectado y vulnerable. En efecto, dado que todo cuerpo se caracteriza por la condición de ser afectado por otros y por la de ser dependiente de las relaciones que hacen posible su vida y acciones, está expuesto a la vulnerabilidad; ésta se hace real cuando faltan las condiciones infraestructurales que harían posible su vida y acciones. La vida de cualquier cuerpo desprovisto de ese apoyo se convierte en vida impensable, en vida precaria. Así pues, la vulnerabilidad y la dependencia no son ya precariedad real (o explotación $\left.{ }^{7}\right)$, sino posibilidad de ello.

${ }^{6}$ Téngase en cuenta que cuando Butler menciona la expresión "marcos" no habla "simplemente de perspectivas teóricas que traemos a colación para analizar la política, sino de modos de inteligibilidad que fomentan los funcionamientos del Estado y, como tales, ellos mismos son ejercicios de poder al tiempo que exceden el ámbito específico del poder estatal" (Butler 2010, 207).

${ }^{7}$ En Los sentidos del sujeto Butler habla de explotación (Butler 2016, 18). 
Todo esto permite entender la tesis materialista defendida por Butler de que un cuerpo es menos una entidad que una relación. Y es que ningún cuerpo llegar a ser nada sin las condiciones infraestructurales y ambientales que posibilitan su existencia (Butler 2015). Así mismo, se entiende que en el control de esas condiciones, en su regulación, eliminación o fomento, descansa tanto la distribución desigual de la precariedad y la consiguiente instauración de diversas formas de dominación y opresión, como la política de resistencia que da lugar a la representación (o perfomance) de nuevas identidades de género, de nuevas vidas pensables.

En este contexto teórico la resistencia se entiende de manera obvia, es decir, como oposición a las normas de identidad excluyentes, como oposición a la presión que ejercen para ser cumplidas, como oposición a la falta de condiciones infraestructurales que convierte en impensables y precarias otras vidas. En definitiva, la resistencia es presentada como una actividad política cuyo sentido y fruto brota por oposición a los marcos que regulan la percepción y las disposiciones afectivas de las vidas (Butler 2011, 24). En conclusión, la resistencia es una oposición a los marcos normativos que establecen una distribución diferencial entre las vidas pensables y valiosas frente a las que no lo son, es decir, entre aquellas vidas que merecen dolor o duelo y las que no. Pero es también una oposición que busca hacer pensables y valiosas otras vidas; busca abrir el espacio social a nuevas formas de género mediante la desviación performativa (y resignificación) de las cadenas citacionales de las normas ${ }^{8}$.

Es precisamente a propósito de este aspecto de su ontología social que Butler expone el principio normativo que acompaña a su concepción de la política como resistencia y performatividad: "todos debemos luchar para superar-en nombre de un mundo interdependiente y dentro de los términos de una forma más radical de igualitarismo- la desigualdad que caracteriza la diferencia entre las vidas por las que se puede llevar duelo y las que no lo merecen" (Butler 2011, 29).

Así pues, la filosofía política butleriana, tan atenta a la diferencia, es igualitarista, pero en un sentido más radical que el usual. ¿Qué puede querer decir esto?

\section{IGUALDAD RADICAL, VÍNCULO SOCIAL Y POLÍTICAS DE ALIANZA}

Para responder a esa pregunta puede ser útil contrastar la perspectiva de $\mathrm{Bu}-$ tler con la clásica. Recuérdese que el igualitarismo clásico, moderno, se configura en su origen de la mano de la noción de derechos naturales. Éstos eran

\footnotetext{
${ }^{8}$ Quizá no está de más señalar que en "Repensar la vulnerabilidad y la resistencia” Butler recordó que ella nunca prescribió qué performances de género eran correctas, o más subversivas, y cuáles eran incorrectas y reaccionarias.
} 
entendidos como atributos propios de los seres humanos, esto es, como características propias y ontológicamente anteriores a los marcos y a los contextos sociales, políticos y culturales en los que los humanos pudieran desarrollar sus vidas. Además, los derechos fueron considerados universales en virtud de una concepción unificada de la especie, por la que los seres humanos estarían vinculados entre sí como iguales al compartir algún rasgo de identidad también anterior a los mencionados marcos. Los rasgos más habituales eran o la capacidad de usar la razón, o la capacidad el ser sensibles, o ambas cosas convenientemente jerarquizadas según si la filosofía era más racionalista o más empirista. Con la irracionalización postestructuralista (y postmoderna) del sujeto moderno y sus rasgos de identidad universales, se pierde ese asidero normativo que era lo que igualaba y vinculaba a los humanos. Con ello se pierde también el punto de apoyo que justificaba tanto las nociones colectivas de sujeto como la defensa de políticas igualitarias de derechos.

La propuesta política de Butler pretende recuperar ambas cosas, los sujetos colectivos y la noción de igualdad política. Como se ha visto en la cita de arriba, Butler considera que su igualitarismo es más radical y, probablemente, con eso quiera decir que descansa en un vínculo primario entre los humanos. Este no puede ser otro que el que supone la ya mencionada mutua dependencia y vulnerabilidad.

Es decir, que lo que vincula a unos seres humanos con otros no son unas capacidades epistémicas y morales, sino esa dependencia que nos expone a los otros y que siempre deja abierta la posibilidad de la precariedad vital. De este vínculo afirma Butler que "no es precisamente una condición en la que se entra mediante la volición y la deliberación; precede al contrato y a menudo se desvanece tras esas formas de contrato social que dependen de una ontología de individuos volitivos. Estamos ligados al extraño, a aquel, o aquellos, a los que nunca conocimos y nunca escogimos" (Butler 2011,34-35). De ahí que no haya lugar a la idea de un sujeto entendido como individuo desvinculado de los demás, que pudiera decidir desde sí vincularse con los demás. La dependencia que cada cuerpo tiene de otros cuerpos y de redes de apoyo forma parte de lo que es un cuerpo individual, pues éste no es nada sin los vínculos que hacen posible su vida. Por todo ello afirma Butler que la performatividad no puede reducirse a la idea de performance individual (Butler 2015).

En esta reflexión llama la atención el que, después de todo, parece que Butler atribuye a los seres humanos una característica común y constitutiva, que ya llega a los marcos cargada de significado normativo igualitarista. En efecto, aunque la secuencia dependencia mutua/vulnerabilidad/precariedad se desarrolla y precisa de manera diferenciada en los distintos marcos, sin embargo no es por sí misma algo vacío de significado, dado que en todos los casos com- 
porta obligaciones (Butler 2011, 35 y ss.). Ahora bien, contra lo que puede parecer a primera vista, las obligaciones que conlleva la norma igualitaria que permite dirimir lo que es una vida vivible, no atañen a los procesos de la vida en sí (la muerte o la destrucción), sino a las condiciones que hacen posible una vida vivible. Con palabras de la propia pensadora: "nuestras obligaciones surgen de la idea de que no puede haber una vida sostenida sin esas condiciones sostenedoras y de que esas condiciones son, a la vez, una responsabilidad política nuestra y la materia de nuestras decisiones éticas más arduas" (Butler 2010, $43)^{9}$. Más adelante volveré sobre el tema de que la mutua dependencia y vulnerabilidad sea una característica común y constitutiva de los humanos. Lo haré para defender que opera como una condición existencial. Pero antes de eso voy seguir con la caracterización de la noción butleriana de política teniendo en cuenta su concepción del vínculo social.

Hasta el momento hemos señalado como Butler dota de sentido preciso a la performatividad y la resistencia políticas al explicarlas a través de la mutua dependencia y vulnerabilidad de los cuerpos. Pero ahora hay que añadir que, tomando pie en la mutua dependencia y la vulnerabilidad, Butler ofrece observaciones importantes sobre las políticas de alianza a través de la diferencia. Así, Butler describe las alianzas como políticas que luchan contra las condiciones de precariedad y persiguen una "universalización más enérgica de los derechos" (Butler 2010, 50). Son políticas cuyo objetivo es "combatir tanto el racismo como la homofobia, combatir tanto la política antiinmigración como las varias formas de misoginia y pobreza inducida" (Butler 2011, 43). Aquí radica el sentido profundo de la defensa, ya mencionada, que realiza Butler de la prioridad de la igualdad social como condición de la libertad.

A esto añade Butler que las posiciones de los grupos participantes en esas políticas de alianza "no son tanto identidades como modos de vida en relación con los otros y los ideales guía" (Butler 2011, 46). También lo expresa de forma similar cuando afirma que "las alianzas movilizadoras no se forman necesariamente entre sujetos establecidos y reconocibles, ni dependen de negociar unas reivindicaciones identitarias" (Butler 2010, 223-224). Estas afirmaciones resultan un tanto enigmáticas a no ser que las interpretemos como una manera de mantener alejada la perspectiva estática y atomizada del sujeto político. En efecto, los modos de vida evidencian en acto, entre otras cosas, las normas que condicionan la identidad de las personas y sus ideales. Por tanto, es en el nivel de los modos de vida donde hay que forjar las alianzas para la persecución conjunta de objetivos políticos compatibles con no condenar a lo impensable determinadas formas de vida.

${ }^{9}$ Esta precisión sobre el campo de referencia de las obligaciones es fundamental en el pensamiento de Butler para la defensa del derecho al aborto. 
Para llegar a ese nivel profundo, Butler sostiene que toda alianza debe adoptar ante todo una práctica de pensamiento crítico, la cual consistiría en cuestionar la existencia de esos sujetos diferenciados que se enfrentan cuando no hay alianza. Sujetos que ya existen en un espacio público común en el que se enfrentan y que, no obstante, buscan la manera de resistir conjuntamente. Cuando la política de alianzas se ejerce como práctica de pensamiento crítico, entonces el interés primordial de toda alianza no serán las identidades, sino el propio marco en el que se da el enfrentamiento y el modo en que ese marco contribuye a alimentarlo mediante la determinación normativa de las identidades, de suerte que unas resulten vidas pensables y otras impensables. Es decir, según el análisis de Butler, la raíz del enfrentamiento entre grupos sociales no se encuentra en que lo que caracteriza su identidad sean rasgos mutuamente irreconciliables, sino en que el marco normativo "exige y produce a dichos sujetos en mutuo conflicto" (Butler 2010, 207). Bajo esta luz los sujetos mismos en liza aparecen como una serie dinámica de relaciones sociales (Butler 2010, 223) que pueden o bien contribuir a ese antagonismo, o bien resistir a él aliándose frente a la fuente que lo instituye. Así pues, podríamos concluir que la alianza política implica resistir ante las normas que hacen antagónicos los modos de vida que sustentan las identidades. Al mismo tiempo implica la necesidad de modificar perfomativamente y en alguna medida sus modos de vida.

El valor de las políticas de alianza así entendidas es doble. Por un lado, es una manera de enfrentarse al marco que hace prescindibles las vidas de determinados colectivos humanos que necesitan "tanto el reconocimiento como la emancipación" (Butler 2011, 45). Por otro lado y al mismo tiempo, las políticas de alianza son el camino para acabar con el modo en que ciertos Estados democráticos se aprovechan de la fragmentación de los sujetos políticos colectivos y usan la defensa identitaria de determinadas libertades para privar de libertades a otros colectivos, mediante el aumento de los mecanismos de coerción $\mathrm{y}$ el incremento de proyectos racistas ${ }^{10}$.

${ }^{10}$ Cuando Butler hizo estas reflexiones en 2010 pensaba especialmente en las políticas migratorias de los estados europeos. En su conferencia de 2015 "Repensar la vulnerabilidad y al resistencia", Butler señala que la apropiación de la "vulnerabilidad" por parte de los poderes dominantes designa que son sus privilegios lo que se ha vuelto algo vulnerable por las crecientes demandas de igualdad y libertad. Así mismo, muestra Butler que ese uso del concepto oscurece la condición de vulnerabilidad en la que viven las poblaciones precarias y, al mismo tiempo, es un secuestro ideológico del término con el fin de expandir y racionalizar las desigualdades.

Desde 2015 la tendencia a la apropiación cínica de tales categorías se ha reforzado extraordinariamente. Baste recordar que el triunfo del presidente estadounidense Donald Trump se ha debido en gran parte a una retórica identitaria supremacista blanca, que enfrenta a los colectivos blancos empobrecidos (o inseguros de su posición económica) contra los inmigrantes y otros colectivos (de género y raza) que, supuestamente, reciben beneficios sociales a costa de detraer 
Así pues, cabe concluir que la concepción de la política que ofrece Butler es verdaderamente compleja y polisémica. Para empezar, se entiende como performatividad de la identidad, pero queer, lo cual la enlaza con la resistencia tanto a las normas de identidad hegemónicas como a los reduccionismos que anulan las normas de identidad alternativas. Y, junto con ello, la política se entiende como una actividad que permite forjar alianzas entre modos de vida. El objetivo general de la política viene marcado por un principio de igualdad, que tiene como condición ontológica de posibilidad la mutua dependencia y vulnerabilidad de cada vida humana.

\section{ALGUNOS CABOS SUELTOS}

No cabe duda de que la noción de política propuesta por Butler es rica, profunda y atenta a la complejidad de nuestro entorno socio-político globalizado. Sin embargo, hay algunos cabos sueltos que expondré brevemente, pues atañen a cuestiones relevantes.

El primero tiene que ver con la política como alianza y, más en concreto, con la afirmación de Butler de que no imagina una alianza completa, es decir, que no imagina que una alianza resuelva los antagonismos. A este respecto expresa su acuerdo con la idea de E. Laclau y Ch. Mouffe de que el antagonismo entre las partes mantiene siempre abierta la alianza y, al mismo tiempo, elimina la meta de la reconciliación (Butler 2010, 206) ${ }^{11}$. Sin embargo, considero que esta afirmación es inconsistente con su propuesta política. En efecto, sin un ápice de reconciliación posible, entonces cualquier alianza para resistir a las normas de identidad (esas que configuran a la partes en liza como antagónicas) solo obtendría como resultado la oposición común al marco estatal hegemónico que sustenta las normas. Pero este es un resultado en cierto modo nihilista, puesto que semejante resistencia no trae de su mano, automáticamente, ni el más modesto objetivo de minimizar la precariedad de manera igualitaria ${ }^{12}$. Este solo puede ser fruto de la dimensión performativa de la resistencia y, en esa medida, de la acción concertada de los grupos aliados. Pero no puede haber acción concertada sin algún grado y tipo de reconciliación entre sus modos de vida. La alianza en la resistencia sin algún tipo de reconciliación, por muy contingente

bienes a los blancos empobrecidos. Esta estrategia de enfrentar entre sí a colectivos precarios, o que se sienten vulnerables, tiene éxito porque oscurece la fuente de su precariedad y, al mismo tiempo, impide que se alíen contra el poder que genera esa precariedad.

${ }^{11}$ Cuando Butler hace esta precisión habla del caso concreto del antagonismo entre minorías sexuales y minorías religiosas.

${ }^{12}$ Sin embargo, en la p. 84 de Marcos de guerra Butler afirma que esa sigue siendo la tarea de la política. 
y parcial que sea, es estéril a largo plazo. O bien el objetivo ético de igualdad se mantiene y amalgama la dinámica de la alianza hasta generar alguna sutura, o bien el antagonismo entre las partes cobrará fuerza por falta de modificaciones en los modos de vida y no habrá alianza. Algo que, por lo demás, siempre será alentado por el poder estatal hegemónico, pues la fragmentación y enfrentamiento entre modos de vida más vulnerables, o directamente precarios, refuerza al poder responsable de la distribución desigual de la precariedad.

Quizá esta inconsistencia teórica se desvanecería si Butler precisara algo más su modelo alternativo de Estado. Lo menciona varias veces en sus textos cuando apela a la necesidad de contar con una democracia sensible. No está muy claro qué entiende por tal versión de la democracia, aunque es evidente que está muy alejada de la mera actividad instrumental que permite la fijación de mayorías. Por el contrario, de forma explícita la conecta con la movilización política contra todas las manifestaciones de la violencia de Estado; con la movilización política que ejercita la libertad en conjunción con la igualdad (Butler 2011, 46). Así mismo, la liga con la reanimación del mundo sensorial y con la movilización total de la expresión de los sentidos al servicio de una vida libre y vivible (Butler 2015). Sin embargo, estas aclaraciones no acaban de precisar el modelo de democracia. No obstante, para nuestros propósitos en este texto basta con atender a la mención a la vida vivible para reparar en que cualquiera que fuera la forma en que se concretara esa demanda de una vida vivible, ya sería una sutura del antagonismo, es decir, algún tipo de reconciliación. Esto se deriva sin inconsistencia del propio análisis de Butler. Eso sí, la reconciliación siempre sería contingente, puesto que en un mundo social de cuerpos que consisten en un conjunto dinámico de relaciones, los términos de la reconciliación pueden quedar obsoletos, o simplemente desaparecer.

Un segundo cabo suelto que me gustaría comentar no atañe tanto a la teoría de Butler, cuanto a una determinada interpretación de la misma. Para mostrarlo es preciso retomar algo de lo ya expuesto.

Recuérdese la conexión que Butler realiza de la mutua dependencia con la obligación moral de oponerse a la destrucción de las condiciones que hacen vivibles las vidas. Recuérdese que esto conlleva seguir el principio normativo de la igualdad radical como guía de la lucha política. De modo que, en el plano político, la igualdad (de condiciones infraestructurales) es una condición para evitar que "se tornen prescindibles y precarias aquellas vidas que necesitan tanto el reconocimiento como la emancipación" (Butler 2011, 45). Como ya se ha señalado, los objetivos políticos concretos que Butler liga a esta perspectiva teórica son combatir el sexismo, la homofobia, la política antiinmigración, las distintas formas de misoginia y la pobreza inducida. De modo que la concepción butleriana de la política se enfrenta tanto a las nuevas formas de opresión como 
a algunas tan clásicas como la lucha contra la pobreza (propia de las políticas de redistribución), o la lucha por la emancipación. Ambas inclusiones son muy importantes, aunque sólo sea porque roturan el campo de posibles alianzas.

Dicho esto, mi comentario se refiere a la inclusión de la emancipación en la concepción butleriana de la política, pues en los últimos años esta categoría parece haber sido abandonada por los colectivos "postfeministas" y condenada a la desaparición. Semejante fin ha traído de su mano el menosprecio del legado feminista clásico, en cuyas teorías la emancipación siempre jugó un papel central. La razón para ese desprecio se deriva de que se trata de una noción central de los proyectos filosóficos progresistas de la Modernidad ${ }^{13}$. En todos ellos la lucha contra la dominación busca la liberación del grupo de los dominados, es decir, de quienes están subordinados a otro grupo. En todos los casos el objetivo político general es romper la lógica de la dominación y, en esa medida, las condiciones que facilitan su reproducción ${ }^{14}$.

El rechazo a entender la política como emancipación viene, pues, del rechazo a toda la herencia de la Modernidad. Por recogerlas brevemente, las razones para descartar la política como emancipación aluden a la falsa universalidad del sujeto político moderno y, por extensión, del sujeto político del feminismo, que habría dejado fuera de su referente las identidades de género no blancas ni heterosexuales. De este modo se aduce que el propio feminismo de raíz teórica moderna habría contribuido a luchar solo por la liberación de algunas mujeres, lo cual habría reforzado la exclusión y denuesto de otras posibles identidades de género. Así mismo, a lo anterior se añade también que el aparato teórico emancipatorio se ha usado repetidamente durante la guerras de los siglos XX y XXI para legitimar los intereses neoimperialistas de las potencias occidentales ${ }^{15}$.

${ }^{13}$ Los propios del movimiento obrero, del movimiento abolicionista y, por supuesto, de todo el movimiento feminista clásico a partir del siglo XVII, muy especialmente del sufragismo y del feminismo socialista del siglo XIX.

${ }^{14}$ La más célebre sistematización teórica de la lógica de la dominación se encuentra en las páginas que G. W. F. Hegel dedica en su Fenomenología del Espíritu (1807) al análisis de la dialéctica amo/esclavo. También J. S. Mill se refiere a esa misma relación como modelo de toda dominación en El sometimiento de la mujer (1869).

${ }^{15}$ Un ejemplo claro de esto es la invasión de Afganistán en 2001. En aquél momento los medios de comunicación se hacían eco de las declaraciones de los jefes de Estado occidentales, los altos cargos de las Naciones Unidas y los portavoces militares que subrayaban la dimensión humanitaria de esa acción, puesto que supuestamente se llevaba a cabo para luchar contra el fundamentalismo religioso, ayudar a las niñas a ir a la escuela y liberar a las mujeres sometidas al yugo talibán. Los numerosos informes y estudios al respecto son muy elocuentes. Hay acceso fácil a algunos de ellos en http://www.globalresearch.ca/. Por ejemplo, http://www.globalresearch.ca/from-afghanistan-to-syria-womens-rights-war-propaganda-and-the-cia/5329665 
Semejante razonamiento tiene la debilidad de las verdades a medias y se le pueden presentar varias objeciones. La primera es que muestra un conocimiento indiferenciado, confuso y apresurado de la vasta y variada herencia del feminismo moderno. En realidad, el legado del feminismo es fruto de sus condiciones históricas y, ya sólo por eso, es limitado en su alcance. Pero esto sucede con cualquier legado teórico y no solo con el feminista, pues desde ninguna teoría se pueden prever las situaciones históricas futuras, ni las formas que adoptará una dominación, ni las nuevas demandas que surgirán. Sin embargo, el legado feminista no es monolítico ni uniforme. Entre otras cosas, está lleno de diversos debates: desde la interpelación crítica de Soujourner Truth a las sufragistas, hasta el debate decimonónico entre sufragistas y feministas socialistas, o el debate estadounidense iniciado en la década de los 70 del siglo $\mathrm{XX}$ entre feministas liberales, feministas radicales y los colectivos de lesbianas. De toda esa tradición se puede seguir aprendiendo hoy en día. En ella hay un magnífico instrumental teórico con el que se muestran problemas, maneras de hacerlos visibles y abordarlos, formas de argumentar y caminos para irracionalizar las tesis contrarias. Por otro lado, tener vivo el propio legado hace fuerte al feminismo contemporáneo al liberarlo de la etiqueta de perspectiva reciente y sin poso cultural ${ }^{16}$.

Con todo, quisiera subrayar que esta objeción no va dirigida hacia las reflexiones de la propia J. Butler, pues ella misma reconoce que hay diversos usos del legado moderno y diferentes críticas posibles (Butler 2010, 155). La suya es, sin duda, fructífera. De hecho defiende la reapropiación crítica de los términos de la Modernidad por parte de quienes fueron excluidos de ellos con el fin de empujar los límites de tales términos. Esta defensa la presenta a propósito de la noción moderna de universalidad y la reapropiación se expresa en clave performativa como puede verse, por ejemplo, aquí: “...las normas convencionales y de exclusión de universales pueden, a través de reiteraciones perversas, producir formulaciones no convencionales de universalidad que exponen los rasgos limitadores y de exclusión de la primera al mismo tiempo que movilizan un nuevo conjunto de demandas" (Butler, Laclau et al. 2004, 47). Además, por otro lado, Butler rechaza su adscripción al postfeminismo (Soley Beltrán 2010, 45). Por el contrario, se considera a sí misma feminista y afirma que el feminismo es parte crucial de las redes de solidaridad y resistencia, porque la crítica feminista desestabiliza aquellas instituciones cuya razón de ser reside en la reproducción de la desigualdad y la injusticia (Butler 2015).

A la anterior cabe sumar otra objeción a ese desprecio del legado feminista

${ }^{16}$ Algunas de las ventajas de establecer sinergias entre las distintas teorías feministas son destacas por Elvira Burgos (Burgos 2010). 
emancipatorio. En este caso contra la idea de que el uso ideológico y neoimperialista de la emancipación de las mujeres sea una razón válida para despreciar ese tipo de política feminista. La réplica principal sería que no debe confundirse la categoría política de emancipación de las mujeres con la reapropiación de la misma como por parte de quienes desean contar con legitimación para instaurar otra dominación. Ninguna categoría política está libre del riesgo de ser usada al servicio de intereses opuestos a los originarios. Como ya he mencionado, en la actualidad estamos presenciando (y viviendo las consecuencias) en Europa y América el modo en que los partidos neoliberales escorados a la extrema derecha usan las categorías políticas de identidad, diferencia e, incluso, vulnerabilidad, para llevar adelante sus propuestas. Como efecto de ello, ya se han alzado voces que reclaman la necesidad de abandonar ese aparato conceptual y retomar la categoría de clase socio-económica para dar cuenta de toda dominación ${ }^{17}$.

Sin embargo, en el legado feminista se recogen suficientes experiencias de lo que supone ese reduccionismo y el modo en que posterga y oscurece las dominaciones cuyo eje no es económico (aunque se combine con él) ${ }^{18}$. Por eso, considero que lejos de prescindir de las categorías feministas y de género, y sus correspondientes estilos de política, lo mejor es redefinirlas de forma más ajustada a sus objetivos políticos. La razón profunda para hacerlo es que esas categorías siguen siendo iluminadoras para dar cuenta de dominaciones que siguen existiendo. Como la propia Butler hace ver, no todas las luchas de los grupos en competencia responden a la cuestión de la identidad (Butler, Laclau et al. 2004, 173), pero esa es también una lucha. También por ello, habría que esmerarse más en las políticas de alianza para evitar las apropiaciones ideológicas mencionadas.

Con todo y al margen de los usos mendaces del concepto, la emancipación no es otra cosa que el resultado de romper la lógica de una dominación y, por tanto, la dominación misma. Ésta puede ser de tipo económico, racial, colonial, religioso o de sexo/género.

Por su lado, la política de resistencia (tal y como la presenta J. Butler) va contra la dominación (subordinación y opresión) que unos colectivos sociales sufren por razón de su identidad de género. En esta medida, apunta a la necesidad de liberarse de una situación de dominación que les impide desarrollar sus vidas como los demás. Y, precisamente, en eso consiste emanciparse.

Para finalizar aludiré a un tercer cabo suelto. En esta ocasión tiene que ver, por un lado, con la noción de mutua dependencia y vulnerabilidad como con-

${ }^{17}$ Sirvan de ejemplo los siguientes textos: Hudson 2016. Sperber 2016. Jenkins 2016.

${ }^{18}$ Cf., por ejemplo, Hartmann 1980 y Weinbaum 1978. 
dición constitutiva de los cuerpos humanos y, por otro, con la afirmación butleriana de que su propuesta política comporta la reclamación de una universalización más enérgica de los derechos.

Como ya se ha recogido antes, la propia pensadora asegura que se guía por un principio normativo de igualdad, algo que la inserta una tradición de pensamiento muy concreta que incluye al feminismo. Sin embargo y como es habitual y lógico, su pensamiento tiene importantes diferencias con la tradición a la que se adscribe. Una muy importante reside en que la demanda de igualdad política y social, propia de las teorías feministas anteriores, remitía teóricamente a una igualdad onto-epistémica de capacidades. Independientemente de las diferencias entre las diversas teorías, las capacidades fueron presentadas como universales para la especie, y previas a los marcos histórico-culturales en lo que hace a su significado y funciones. A partir de aquí, tomando pie en ellas, se presentaba como justificada y legítima la demanda de igualdad política y social, la cual se concretó en diversas reclamaciones críticas de derechos de ciudadanía política, social y civil ${ }^{19}$.

Como también se ha dicho páginas atrás, la defensa de la igualdad política y social que efectúa Butler remite teóricamente a algo distinto: a la condición de dependencia mutua y vulnerabilidad. Pues bien, esto constituye, en su caso, la instancia de justificación ${ }^{20}$ de la demanda de derechos ciudadanos respetuosos con las diferencias de género y sus correspondientes modos de vida. Así pues, en la estructura formal del pensamiento butleriano, esa condición cumple la misma función que las capacidades humanas en las teorías feministas previas. En ambos casos son fuentes de justificación de la demanda de igualdad política y social.

Pero también cabe ver otra coincidencia, pues en ambos casos la especie humana $^{21}$ queda unificada por algo que comparten los especímenes. Entonces, ¿se podría decir que la condición de mutua dependencia y vulnerabilidad es una condición existencial universal, como mínimo, para los cuerpos humanos?

Butler se muestra reticente a semejante afirmación. Las razones para ello aparecen resumidas hacia el final de su conferencia "Repensar la vulnerabilidad y al resistencia". Ahí se puede ver como lo que le preocupa de semejante

${ }^{19}$ Uso aquí la clasificación empleada por N. Fraser y L. Gordon (Fraser y Gordon 1992).

${ }^{20}$ Presupongo aquí la distinción epistemológica entre justificación y fundamentación absoluta. Es decir, que no toda justificación es fundamentalista. Hay nociones falibilistas de justificación y alguna de ellas podría tener cabida en el pensamiento de Butler.

${ }^{21}$ En varias teorías encontramos que lo que vincula a la especie humana también la conecta con otros animales. Esta idea la defiende Butler, pero también, por ejemplo, J. S. Mill y H. T. Mill que unifican a la especie humana (y la vinculan con los otros animales) por su capacidad de ser sensibles y de buscar el placer y evitar el dolor. 
interpretación es que la vulnerabilidad se entienda como fuente de un nuevo modo de autenticidad, de valores morales auténticos afines, por ejemplo, a la noción de "cuidado". Si fuera así, ciertamente sería preocupante, pues supondría una recaída en el esencialismo. Para evitarlo Butler subraya que su noción de vulnerabilidad no alude ni a una característica meramente pasiva, ni a una disposición subjetiva. Por el contrario, la define como una característica a un tiempo pasiva y activa; como algo propio del animal humano (y otros animales) que es capaz tanto de ser afectado como de actuar. Más en concreto, la piensa como factor inseparable de la de resistencia y, por ello, de la capacidad de acción política de los agentes tal y como los hemos descrito páginas atrás. En definitiva, la vulnerabilidad mencionaría un "conjunto de relaciones entre seres sensibles y el campo de fuerza de objetos, organizaciones, procesos vitales e instituciones que constituyen la posibilidad misma de una vida vivible" (Butler 2015, párrafo final). Así vista, la vulnerabilidad no conlleva ningún prototipo esencial y normativo de autenticidad, pues las relaciones siempre son inestables, variables y contingentes. Sí conlleva, como ya se ha dicho, un compromiso con un principio de igualdad radical, pero su realización tampoco es unívoca ni homogénea, puesto que está sujeta también a las variaciones de las relaciones y de los campos de fuerza mencionados.

Ahora bien, admitiendo todas estas precisiones, ¿no sigue siendo la mutua dependencia y la vulnerabilidad una condición existencial común (al menos) para los humanos en tanto que seres relacionales? Si se acepta la concepción antiesencialista de los humanos como cuerpos que llegan a ser lo que llegan a ser en virtud de sus relaciones de mutua dependencia con los otros cuerpos; si se acepta que eso implica la capacidad, a un tiempo pasiva y activa, de vulnerabilidad y resistencia, entonces ¿por qué no se puede decir que esa es su condición existencial común?, ¿es que hay algo misterioso que por definición impida pensar en una condición existencial que no sea una esencia? No creo que lo haya. Es más, la propuesta de Butler seria prueba de ello, puesto que ofrece una condición existencial que no es una esencia, sino una disposición (a un tiempo pasiva y activa) que se concreta de forma variable y adopta tantas modalidades como modos de vida se den.

Por lo demás, admitir esta interpretación tiene valiosas ventajas. Una de ellas es que facilita el ejercicio del pensamiento crítico contra las apropiaciones ideológicas que sólo buscan defender privilegios y, de ese modo, refuerzan y extienden la desigualdad. Esto se debe, precisamente, a que la mutua dependencia y la vulnerabilidad se evidencia como condición existencial en aquellas situaciones en las que se muestra, mediante comparación, lo que supone para ciertos cuerpos vulnerar los privilegios anexos a su modo de vida, y lo que su- 
pone para otros cuerpos vulnerar sus derechos al cercenar su red de relaciones e infraestructuras hasta el punto de hacer literalmente invivible su vida.

Otra ventaja de entender esta noción antiesencialista de mutua dependencia y vulnerabilidad como condición existencial, es que permite evitar los desarrollos nihilistas de las alianzas políticas. En efecto, la vulnerabilidad es presentada por Butler como una disposición cuya faceta activa consiste en resistir, es decir, en oponerse a la condena a una vida no vivible y conseguir que cambien las relaciones que generan vidas precarias, de modo que se abra el espacio social a modos de vida diferentes. Sin embargo, como he argumentado antes, para ello sería preciso aceptar la posibilidad de que los antagonismos pudieran dar pie a alguna alianza que alcance una reconciliación contingente.

Por último, sugeriré una tercera ventaja, aunque no la voy a desarrollar porque el tema merecería un estudio más extenso del que cabe aquí. Páginas atrás recogí el comentario de Butler sobre que la nueva política de alianzas contingentes no rechaza los universales, sino que los entiende como un destello que cobra existencia durante un período limitado en los lugares donde se sitúa el poder (Butler 2000, 114). En esta manera de concebir los universales Butler coincide con Linda Zerelli al presentarlos como un logro frágil, cambiante y siempre incompleto de la acción política (Butler, Laclau et al. 2004, 39 y ss.). A ello añade que diversos movimientos sociales pueden operar con nociones de universalidad que estén en competencia (Butler et al. 2004, 168), por lo que la política de alianzas debería solventar este escollo so pena de impedir la alianza. Ante esta dificultad Butler argumenta que el logro se alcanza mediante un acto constitutivo de traducción cultural postcolonial, cuyo resultado no es una fusión final de todos los horizontes culturales (Butler et al. 2004, 27). Más bien, lo que resulta (entre otras cosas) es una puesta en evidencia de que los grupos en liza no pertenecen a un espacio común y, junto a ello, resulta un desplazamiento mimético del original y una apropiación y renovación del término que lo separa de su autoridad putativa (Butler et al. 2004, 44).

Pues bien, quizá estas breves notas sean suficientes para entender mi sugerencia. Expresada brevemente: esta concepción de los universales, que destellan gracias a ese acto constitutivo de traducción cultural postcolonial, sólo se entiende a la luz de la mutua dependencia y vulnerabilidad como condición existencial (no esencialista) que va enlazada con el principio de igualdad. Y es que es la conciencia de esa condición existencial la que permite ver los diversos universales contingentes como evidencias diferentes y cambiantes de lo que la universalidad abstracta ha excluido al ocultar sus límites contingentes. Es tomando conciencia de esa condición existencial como se torna posible el ansiado desplazamiento de los límites de los universales. 
Para concluir, añadiría que estos comentarios a los cabos sueltos no tienen como fin invalidar la concepción butleriana de la política, sino contribuir a seguir analizando su potencial. Éste procede de la ausencia de nihilismo que caracteriza la noción butleriana de política como resistencia. Como se ha expuesto, la originalidad de esta noción de resistencia deriva del fondo materialista que la anima. Desde ahí se perfila también como una actividad performativa y abierta a aquellas alianzas políticas que estén guiadas por una forma radical de igualitarismo, siempre en aras de abrir el espectro de las vidas pensables y vivibles.

\section{BIBLIOGRAFÍA}

Benhabib, S. et al. (1995), Feminist Contentions: A Philosophical Exchange, New York/ London: Routledge.

Butler, J. (2000), "El marxismo y lo meramente cultural", en New Left Review, n 2, mayo-junio, pp.109-121.

Butler, J., Laclau, E. y Žižek, S. (2004), Contingencia, hegemonía, universalidad, Buenos Aires: FCE.

Butler, J. (2010), Marcos de guerra, Barcelona: Paidós.

Butler, J. (2011), Violencia de Estado, guerra, resistencia. Por una nueva política de la izquierda, Madrid: Katz.

Butler, J. (2015), "Repensar la vulnerabilidad y la resistencia". Conferencia impartida el 24 de junio de 2015 en el marco del XV Simposio de la Asociación Internacional de Filósofas (IAPh), Alcalá de Henares. https://www.youtube.com/ watch? $\mathrm{v}=\mathrm{hEjQHv0R6rQ}$

Butler, J. (2016), Los sentidos del sujeto, Barcelona: Herder.

Burgos, E. (2010), “Cruzando líneas. Trazando conexiones”, en Feminismo/s, Alicante: Universitat d'Alacant / Universidad de Alicante: Instituto de Investigación de Estudios de Género, ${ }^{\circ} 15$, pp. 33-54.

Fraser, N, y Gordon, L. (1992), "Contrato versus caridad: una reconsideración de la relación entre ciudadanía civil y ciudadanía social", en Isegoría, Madrid: Instituto de Filosofía del CSIC, nº 6 , pp. 65-82.

Fraser, N. (2000), "Heterosexismo, falta de reconocimiento y capitalismo: una respuesta a Judith Butler", en New Left Review, n 2, mayo-junio, pp. 123-136.

Hartmann, H. (1980), "Un matrimonio mal avenido: hacia una unión más progresiva entre marxismo y feminismo", en Zona Abierta, 24, pp. 85-113.

Hudson, M. (2016), "EE UU: La elección de Trump ha decretado la muerte definitiva de la política basada en las identidades", en Sin permiso, 17/11/2016. www.sinpermiso.info. 
Jenkins, S. (2016), "Culpad a los apóstoles de la identidad, ellos nos empujaron al camino del populismo", en eldiario.es, 4/12/2016.

Perona, A. J. (2003), "Sexo y género. De la imposibilidad del constructivismo radical", en Riff-Raff, vol., 21, 2a, pp. 100-109.

Soley Beltrán, P. (2010), "De literatura, mitos y estrellas. Entrevista con Judith Butler", en revista Minerva, Madrid: Círculo de Bellas Artes, IV Época, nº 13, pp. 43-46.

Sperber, J. (2016), “Trump, en la era de las políticas identitarias", en Sin permiso, 11/12/2016. www.sinpermiso.info.

Weinbaum, B. (1978), El curioso noviazgo entre feminismo y socialismo, Madrid, Siglo XXI. 